\title{
Analysis of overlapping surgery in patients undergoing microsurgical aneurysm clipping: acute and long-term outcomes from the Barrow Ruptured Aneurysm Trial
}

\author{
Michael A. Mooney, MD, Scott Brigeman, MD, Michael A. Bohl, MD, Elias D. Simon, BA, \\ John P. Sheehy, MD, Steve W. Chang, MD, and Robert F. Spetzler, MD \\ Department of Neurosurgery, Barrow Neurological Institute, St. Joseph's Hospital and Medical Center, Phoenix, Arizona
}

\begin{abstract}
OBJECTIVE Overlapping surgery is a controversial subject in medicine today; however, few studies have examined the outcomes of this practice. The authors analyzed outcomes of patients with acutely ruptured saccular aneurysms who were treated with microsurgical clipping in a prospectively collected database from the Barrow Ruptured Aneurysm Trial. Acute and long-term outcomes for overlapping versus nonoverlapping cases were compared.
\end{abstract}

METHODS During the study period, 241 patients with ruptured saccular aneurysms underwent microsurgical clipping. Patients were separated into overlapping $(n=123)$ and nonoverlapping $(n=118)$ groups based on surgical start/stop times. Outcomes at discharge and at 6 months, 1 year, 3 years, and 6 years after surgery were analyzed.

RESULTS Patient variables (e.g., age, smoking status, cardiovascular history, Hunt and Hess grade, Fisher grade, and aneurysm size) were similar between the 2 groups. Aneurysm locations were similar, with the exception of the overlapping group having more posterior circulation aneurysms (18/123 [15\%]) than the nonoverlapping group (8/118 [7\%]) ( $p$ $=0.0495)$. Confirmed aneurysm obliteration at discharge was significantly higher for the overlapping group (109/119 $[91.6 \%])$ than for the nonoverlapping group $(95 / 116[81.9 \%])(p=0.03)$. Hospital length of stay, discharge location, and proportions of patients with a modified Rankin Scale (mRS) score $>2$ at discharge and up to 6 years postoperatively were similar. The mean and median mRS, Glasgow Outcome Scale, Mini-Mental State Examination, National Institutes of Health Stroke Scale, and Barthel Index scores at all time points were not statistically different between the groups.

CONCLUSIONS Compared with nonoverlapping surgery, overlapping surgery was not associated with worse outcomes for any variable at any time point, despite the complexity of the surgical management in this patient population. These findings should be considered during the discussion of future guidelines on the practice of overlapping surgery.

https://thejns.org/doi/abs/10.3171/2017.5.JNS17394

KEY WORDS microsurgery; outcomes; overlapping surgery; saccular aneurysms; subarachnoid hemorrhage; vascular disorders

$\mathrm{O}$ VERLAPPING surgery is defined as 2 operations being performed by the same primary attending surgeon simultaneously without any overlap of the critical or key portions of the operations..$^{2,3}$ Overlapping surgery is a controversial topic in medicine today, and the safety of this practice has been questioned in recent reports. ${ }^{1,21}$ Concerns about patient safety have led to nationwide changes in surgical scheduling regulations; however, limited data examining this practice exist. No studies published to date have found any evidence of worse outcomes with overlapping surgery; $;, 9,11,23$ however, these studies examined heterogeneous populations of patients undergoing a variety of neurosurgical procedures.

It seems reasonable that, if a difference exists between overlapping and nonoverlapping surgical results, it would be most obvious in patients undergoing a highly complex surgical procedure, such as aneurysm clipping for acute subarachnoid hemorrhage (SAH). We therefore sought to

ABBREVIATIONS BRAT = Barrow Ruptured Aneurysm Trial; GCS = Glasgow Coma Scale; GOS = Glasgow Outcome Scale; LOS = length of stay; MMSE = Mini-Mental State Examination; $\mathrm{mRS}=$ modified Rankin Scale; NIHSS = National Institutes of Health Stroke Scale; $\mathrm{SAH}=$ subarachnoid hemorrhage.

SUBMITTED February 13, 2017. ACCEPTED May 8, 2017.

INCLUDE WHEN CITING Published online November 3, 2017; DOI: 10.3171/2017.5.JNS17394. 
evaluate detailed short-term and long-term outcomes of overlapping surgery in a cohort of patients who underwent microsurgical clipping for acutely ruptured aneurysms at our institution.

The Barrow Ruptured Aneurysm Trial (BRAT) was a prospective, randomized trial of microsurgical versus endovascular treatment of ruptured aneurysms, and results through 6 years of follow-up have been published..$^{15,18,19} \mathrm{To}$ examine outcomes of overlapping surgery, we performed a retrospective review of prospectively collected data from patients with ruptured saccular aneurysms who underwent microsurgical clipping in this trial. We hypothesized that patients in overlapping cases may have worse acute and/or long-term outcomes than patients in nonoverlapping cases.

\section{Methods}

Prospectively collected data from the BRAT were retrospectively analyzed. This analysis was approved by the institutional review board of St. Joseph's Hospital and Medical Center, with exemption from informed consent due to the retrospective nature of the study. The methodology for BRAT is described in detail elsewhere. ${ }^{15,18,19} \mathrm{In}$ brief, patients with nontraumatic SAH who presented to our institution between March 2003 and January 2007 were randomized to undergo either open microsurgical clipping or endovascular coiling of their aneurysms.

The BRAT database includes prospectively collected demographic data, comorbid conditions, aneurysm characteristics, initial Glasgow Coma Scale (GCS) score, ${ }^{20}$ Hunt and Hess $^{10}$ and Fisher ${ }^{7}$ grades, and complicating factors at initial presentation, such as intraventricular hemorrhage or intraparenchymal hemorrhage. Surgical complications were recorded, including intraoperative aneurysmal rupture, rebleeding, postoperative stroke, and wound infection. Other metrics included aneurysm obliteration rate, total hospital length of stay (LOS), discharge location (home, skilled nursing facility, acute rehabilitation center, hospice, death), GCS score at discharge, and qualified outcomes scale scores, such as those of the Barthel Index, ${ }^{14}$ Glasgow Outcome Scale (GOS), ${ }^{13}$ modified Rankin Scale $(\mathrm{mRS}),{ }^{6}$ Mini-Mental State Examination (MMSE), ${ }^{8}$ and National Institutes of Health Stroke Scale (NIHSS; https:// stroke.nih.gov/resources/scale.htm). Outcomes data were collected by a research nurse practitioner at discharge and at 6 months, 1 year, 3 years, and 6 years after initial treatment, with final follow-up scheduled at 10 years. A neuroradiologist not involved with the treatment assessed aneurysm obliteration via conventional angiography, CT angiography, or MR angiography.

Operative data (e.g., the case start and end times) were collected through institutional surgical records. Start time was recorded as the time of surgical incision, and stop time was defined as the time when the incision was fully closed at the end of the case. If the primary surgeon was listed on another operative case on the same day as the aneurysm clipping, start and end times for these cases were evaluated for overlap. Patients were included in the overlapping group if there was any degree of overlap between the operative start and end times between 2 cases, in accordance with the definition of the American College of Surgeons. ${ }^{3}$ All
TABLE 1. Patient variables for nonoverlapping versus overlapping cases

\begin{tabular}{lcc}
\hline \multicolumn{1}{c}{ Variable } & $\begin{array}{c}\text { No Overlap } \\
(\mathrm{n}=118)\end{array}$ & $\begin{array}{c}\text { Overlap } \\
(\mathrm{n}=123)\end{array}$ \\
\hline Mean age in yrs & 54.9 & 54.8 \\
\hline Comorbidities & $81(69)$ & $82(67)$ \\
\hline Smoker & $28(24)$ & $27(22)$ \\
\hline Alcohol or drug abuse & $14(12)$ & $14(11)$ \\
\hline Atherosclerotic disease & $3(3)$ & $6(5)$ \\
\hline Myocardial infarction & $0(0)$ & $1(1)$ \\
\hline Congestive heart failure & $8(7)$ & $7(6)$ \\
\hline COPD & $9(8)$ & $13(11)$ \\
\hline Diabetes mellitus & $60(51)$ & $49(40)$ \\
\hline Hypertension & $5(4)$ & $9(7)$ \\
\hline Malignancy & $6(5)$ & $4(3)$ \\
\hline Renal disease & $4(3)$ & $5(4)$ \\
\hline Stroke & 2.7 & 2.5 \\
\hline Mean Hunt \& Hess grade & 2.8 & 2.7 \\
\hline Mean Fisher grade & $63(53)$ & $69(56)$ \\
\hline Intraventricular hemorrhage & $33(28)$ & $25(20)$ \\
\hline Intraparenchymal hemorrhage & $23(19)$ & $37(30)$ \\
\hline 4th ventricular hemorrhage & $5(4)$ & $4(3)$ \\
\hline Wrapping & $0(0)$ & $2(2)$ \\
\hline Bypass & $109(92)$ & $107(87)$ \\
\hline Ventriculostomy & &
\end{tabular}

COPD = chronic obstructive pulmonary disease.

Values are number of patients (\%) unless indicated otherwise. No significant differences were found between groups.

other patients were included in the nonoverlapping group. All patients in the BRAT who underwent microsurgical clipping of a ruptured saccular aneurysm were included in the analysis.

For statistical analysis, means were compared using the t-test, median values were compared using the MannWhitney U-test, and proportional variables were compared using a chi-square analysis or Fisher's exact test. Outcome scale cutoff values were determined based on those in earlier literature. ${ }^{17,22}$ Results for this study are reported as statistically significant if the $\mathrm{p}$ value was less than 0.05 .

\section{Results}

In the BRAT study, a cohort of 241 patients with ruptured saccular aneurysms underwent microsurgical clipping. The overlapping group comprised 123 patients, and the nonoverlapping group comprised 118 patients. Demographic information (e.g., age, smoking status, comorbidities, initial Hunt and Hess and Fisher grades, presence of intraventricular or intraparenchymal hemorrhage, and aneurysm size) was statistically similar between the 2 groups (Table 1). Patients in the overlapping group were more likely to harbor posterior circulation aneurysms (18/123 [15\%]) than patients in the nonoverlapping group (8/118 $[7 \%])(\mathrm{p}=0.0495)$, largely due to more superior cerebellar 
TABLE 2. Aneurysm characteristics for nonoverlapping versus overlapping cases

\begin{tabular}{lccc}
\hline \multicolumn{1}{c}{ Variable } & $\begin{array}{c}\text { No Overlap } \\
(\mathrm{n}=118)\end{array}$ & $\begin{array}{c}\text { Overlap } \\
(\mathrm{n}=123)\end{array}$ & $\begin{array}{c}\mathrm{p} \\
\text { Value }\end{array}$ \\
\hline $\begin{array}{l}\text { Mean aneurysm size in mm } \\
\text { (range) }\end{array}$ & $6.8(1-25)$ & $6.8(1.5-23)$ & 0.99 \\
\hline Anterior circulation & $110(93)$ & $105(85)$ & \\
\hline Posterior circulation & $8(7)$ & $18(15)$ & 0.0495 \\
\hline Location classified & & & \\
\hline Internal carotid artery & $37(31)$ & $34(28)$ & 0.53 \\
\hline Anterior cerebral artery & $49(42)$ & $49(40)$ & 0.79 \\
\hline Middle cerebral artery & $24(20)$ & $22(18)$ & 0.63 \\
\hline Basilar/vertebral & $5(4)$ & $6(5)$ & 0.81 \\
\hline $\begin{array}{l}\text { Posterior inferior cerebellar } \\
\text { artery }\end{array}$ & $3(3)$ & $8(7)$ & 0.21 \\
\hline Superior cerebellar artery & $0(0)$ & $4(3)$ & 0.12 \\
\hline
\end{tabular}

Values are number of patients (\%) unless indicated otherwise.

artery and posterior inferior cerebellar artery aneurysms in the overlapping group $(12 / 123[10 \%])$ than in the nonoverlapping group (3/118 [3\%]) (Table 2).

Operative outcomes are summarized in Table 3. The mean duration of surgery was 13 minutes longer in the overlapping group than in the nonoverlapping group (259.3 vs 246.4 minutes), which was not statistically significant $(\mathrm{p}=0.21)$. Surgical complications, including rebleeding, intraparenchymal hemorrhage, subdural hematoma, and wound infections, were statistically similar between the 2 groups (16/123 [13\%] overlapping vs 18/118 [15\%] nonoverlapping, $p=0.84$ ). The incidence of clinically significant postoperative stroke with radiographic confirmation was also not statistically significant between the overlapping (9/123 [7\%]) and nonoverlapping (14/118 [12\%]) groups $(p=0.28)$. Hospital LOS, discharge location, and the need for a ventriculoperitoneal shunt were similar between the 2 groups $(\mathrm{p} \geq 0.05)$. Aneurysm obliteration rates at discharge were significantly higher in the overlapping group (109/119 [91.6\%]) than in the nonoverlapping group (95/116 [81.9\%]) $(\mathrm{p}=0.03)$. However, the difference in obliteration rates between the overlapping and nonoverlapping groups was not significant at the 3-year follow-up (91.2\% [52/57] vs $82.1 \%$ [55/67], respectively; $\mathrm{p}=0.19)$ or at the 6-year follow-up (94.5\% [52/55] vs $94.4 \%$ [51/54], respectively; $p>0.99)$. The proportion of patients undergoing formal diagnostic angiography versus CT angiography or MR angiography was similar at all time points, with $\geq 97 \%$ of patients undergoing formal diagnostic angiography at discharge to determine aneurysm obliteration status.

Qualified outcome measures (mean and median mRS, GOS, MMSE, NIHSS, and Barthel Index scores) were not statistically different at discharge or at 1 year, 3 years, or 6 years after initial treatment (Figs. 1 and 2, Table 4). The proportion of patients with high NIHSS scores (21-42) at discharge was significantly higher in the nonoverlapping group than in the overlapping group (Fig. 2E and F). However, there were no statistically significant differences in the proportions of patients in stratified categories
TABLE 3. Patient outcomes for nonoverlapping versus overlapping cases

\begin{tabular}{lccc}
\hline \multicolumn{1}{c}{ Variable } & $\begin{array}{c}\text { No Overlap } \\
(n=118)\end{array}$ & $\begin{array}{c}\text { Overlap } \\
(\mathrm{n}=123)\end{array}$ & $\begin{array}{c}\mathrm{p} \\
\text { Value }\end{array}$ \\
\hline Mean surgery duration in mins & 246.4 & 259.3 & 0.21 \\
\hline Mean hospital LOS in days & 18.6 & 18.7 & 0.94 \\
\hline Surgical complication & $18 / 118(15)$ & $16 / 123(13)$ & 0.84 \\
\hline Postop stroke & $14 / 118(12)$ & $9 / 123(7)$ & 0.28 \\
\hline Shunt dependent & $43 / 118(36)$ & $42 / 123(34)$ & 0.71 \\
\hline SAH rebleed & $1 / 118(1)$ & $0 / 123(0)$ & 0.49 \\
\hline Death & $4 / 118(3)$ & $3 / 123(2)$ & 0.72 \\
\hline Aneurysm obliteration rate & & & \\
\hline Discharge & $95 / 116(81.9)$ & $109 / 119(91.6)$ & 0.03 \\
\hline 3 yrs & $55 / 67(82.1)$ & $52 / 57(91.2)$ & 0.19 \\
\hline 6 yrs & $51 / 54(94.4)$ & $52 / 55(94.5)$ & $>0.99$ \\
\hline Mean GCS score & & & \\
\hline Admission & 14.0 & 14.2 & 0.60 \\
\hline Discharge & 13.8 & 14.2 & 0.38 \\
\hline Discharge location & & & \\
\hline Home & $38 / 111(34)$ & $48 / 119(40)$ & 0.27 \\
\hline Rehabilitation facility & $50 / 111(45)$ & $54 / 119(45)$ & 0.80 \\
\hline Skilled nursing facility & $20 / 111(18)$ & $16 / 119(13)$ & 0.39 \\
\hline Hospice & $3 / 111(3)$ & $1 / 119(1)$ & 0.36 \\
\hline Other & $3 / 111(3)$ & $0 / 119(0)$ & 0.11 \\
\hline Vaues are numbelta & & & \\
\hline & & & \\
\hline
\end{tabular}

Values are number/total number of patients (\%) unless indicated otherwise.

for mRS, GOS, MMSE, Barthel Index, and NIHSS at all other time points.

\section{Discussion}

Overlapping surgery has been a routine practice at many institutions for decades, as it reduces downtime between surgical cases and facilitates scheduling of elective and urgent and/or emergency operations. ${ }^{4}$ This improved efficiency results in greater patient access to specialist care, reduced wait times prior to surgery, and more operations completed during daytime hours. In teaching institutions, overlapping cases are also associated with more resident involvement and graduated autonomy for surgeons in training, which many believe represents an invaluable learning opportunity., ${ }^{4,9,23}$ However, recent reports questioning the safety of overlapping surgery have required surgeons and institutions to address this strategy to ensure that the best possible care is being offered to patients. ${ }^{16,21}$

Few studies have been performed on this subject to date, and recent changes in practice have been driven by anecdotal reports of surgical complications in overlapping or concurrent cases. Guan et al. ${ }^{9}$ published the first series in the neurosurgical literature examining outcomes of overlapping versus nonoverlapping cases at their institution and demonstrated no increase in complications in 475 overlapping cases from a total of 1018 patients. Hyder et al. ${ }^{11}$ recently published their experience with overlapping surgery at the Mayo Clinic in a case-matched statistical 


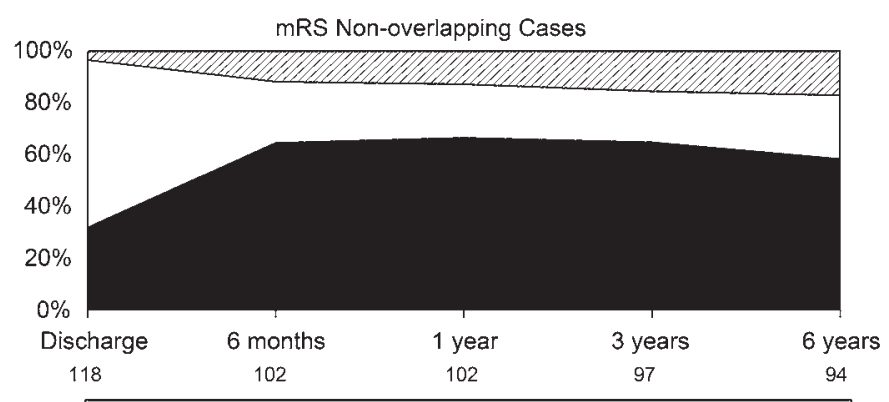

A

- Good Outcome (0-2) $\square$ Disabled (3-5) $\square$ Dead (6)

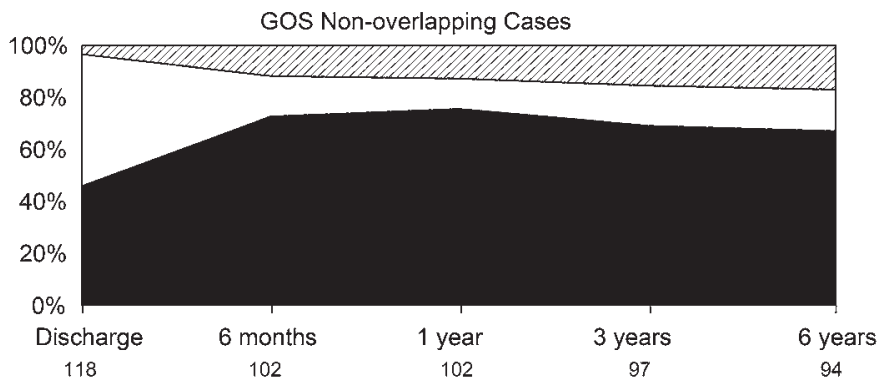

18

102

102

C

- Good Outcome (4-5) $\square$ Disabled or Vegetative (2-3) $\square$ Dead (1)

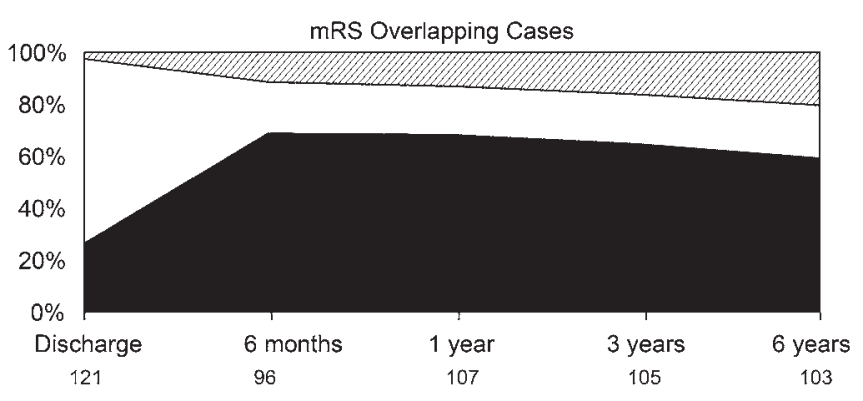

B

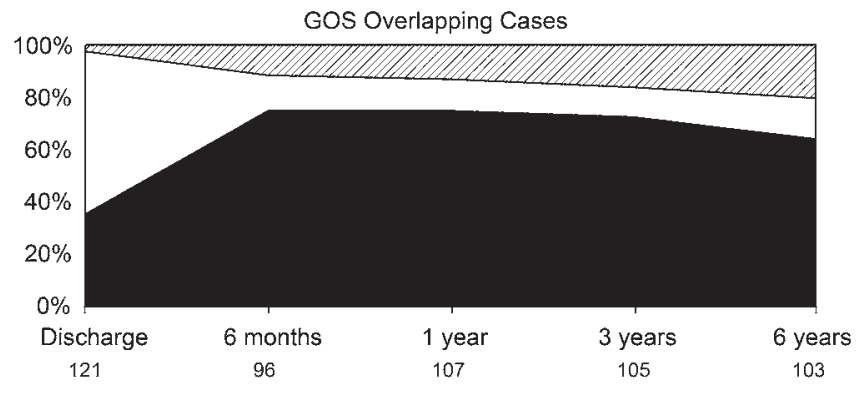

D

FIG. 1. Proportion of patients with the defined outcomes at the corresponding follow-up time points by mRS scores for nonoverlapping (A) and overlapping (B) cases and GOS scores for nonoverlapping (C) and overlapping (D) cases. No significant differences were observed in mean scores, median scores, or comparisons of proportions at any time point. Numbers under the graphs indicate the number of patients at each time point.

model of elective surgical procedures performed in all specialties (e.g., cardiovascular surgery, plastic surgery). Their study showed no evidence of worse outcomes with overlapping surgery as practiced at the Mayo Clinic. Although this study was matched case by case in a statistical model, relative case numbers within each specialty were small, and no conclusions can be made about specific case types from this analysis. Zygourakis et al. ${ }^{23}$ published their single-center, single-provider experience with 1219 vascular neurosurgery cases at the University of California, San Francisco, with results similar to those of earlier studies-variations in case complexity were present between overlapping and nonoverlapping cases, but no evidence of worse outcomes with overlapping surgery was identified in a multivariate analysis.

We sought to evaluate the practice of overlapping surgery in a more homogeneous cohort of patients undergoing microsurgical clipping of an acutely ruptured aneurysm with data from a prospective, randomized trial. We hypothesized that if a negative effect of overlapping surgery does exist, it would be most evident in a complex procedure requiring a high degree of surgical skill, such as ruptured aneurysm clipping.

Several factors are important to consider when interpreting the results of our study. First, at our institution, the practice of overlapping surgery is performed with careful attention by the attending neurosurgeon to case timing, case details, and resident capabilities. Given the often urgent or emergency nature of these procedures, as well as the relatively long opening and closure times in relation to the time required for aneurysm dissection and clipping, overlapping cases of microsurgical aneurysm clipping are often performed at our institution to facilitate scheduling and improve efficiency. Importantly, overlapping surgery is distinguished from concurrent surgery by the lack of overlap of the critical portion of the procedures. In microsurgical aneurysm clipping, we define this portion as the dissection and clipping of the ruptured aneurysm, for which the attending neurosurgeon is uniformly present at our institution.

Second, microsurgical clipping of ruptured aneurysms at our institution is performed nearly uniformly with the assistance of a resident in the final year of residency training or a postgraduate fellow. The experience level of the resident or fellow is always considered on a case-by-case basis by the attending neurosurgeon, and it is of crucial importance in any discussion of overlapping cases. Lastly, all operations included in the BRAT were performed by one of 2 neurosurgeons with extensive experience in microsurgical aneurysm clipping.

Our study considered all patients who underwent microsurgical clipping of a ruptured saccular aneurysm in BRAT, and all data were prospectively collected by a dedicated research team as part of the clinical trial through 6 years of follow-up. Patients in the overlapping and nonoverlapping groups in this study were well matched for comorbidities and clinical presentation with SAH, with the exception of more posterior circulation aneurysms in the overlapping surgery group (Table 1).

Our study has several notable findings. First, aneurysm obliteration rates, as confirmed on postoperative angiography, were higher at discharge for the overlapping group 


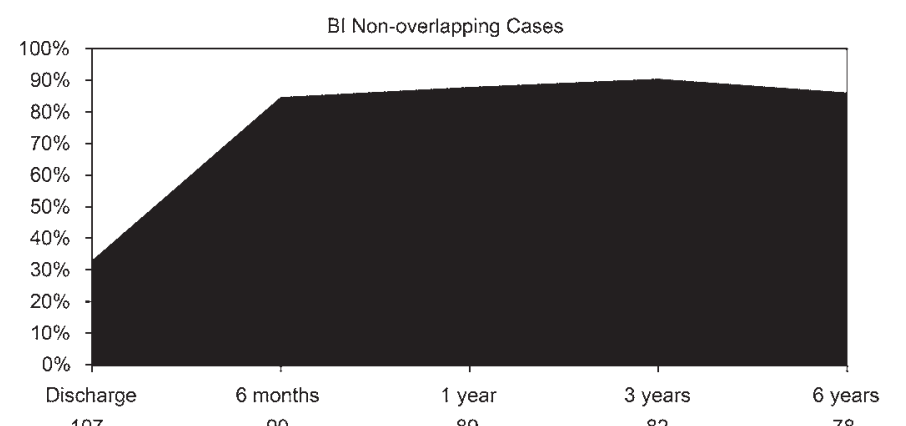

107

A
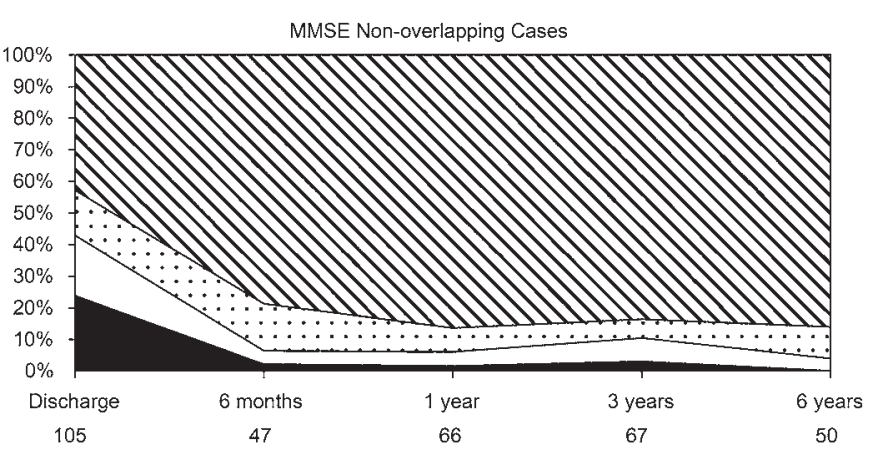

C
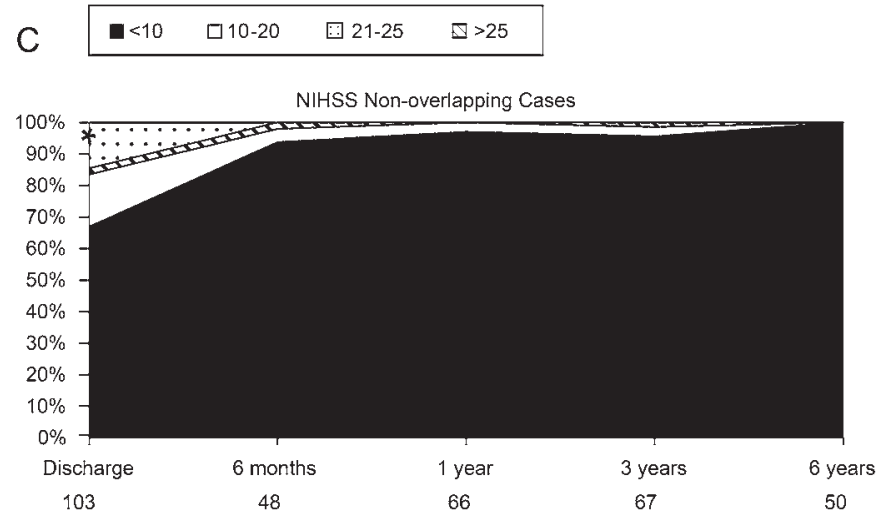

$E$

\begin{tabular}{|c|c|c|}
\hline $\mathbf{\square}$ & 口 5-15 & $\varangle 16-20$ \\
\hline
\end{tabular}

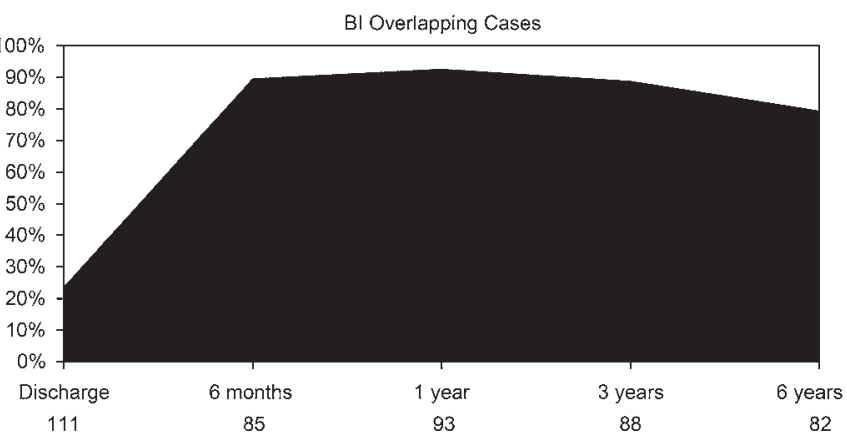

B

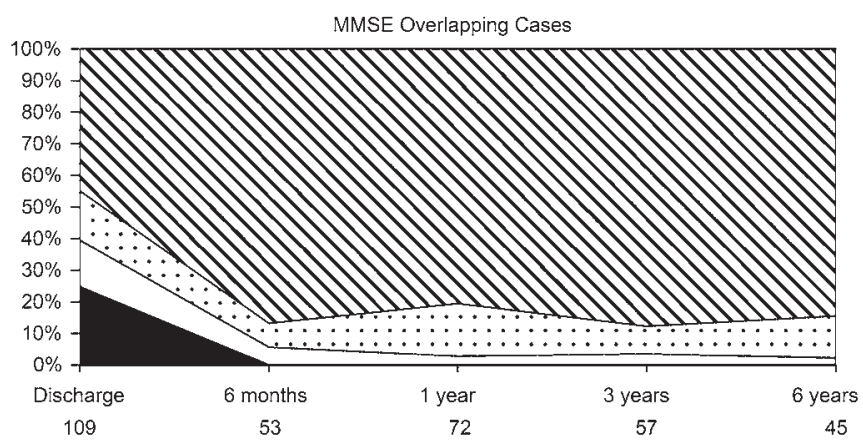

D

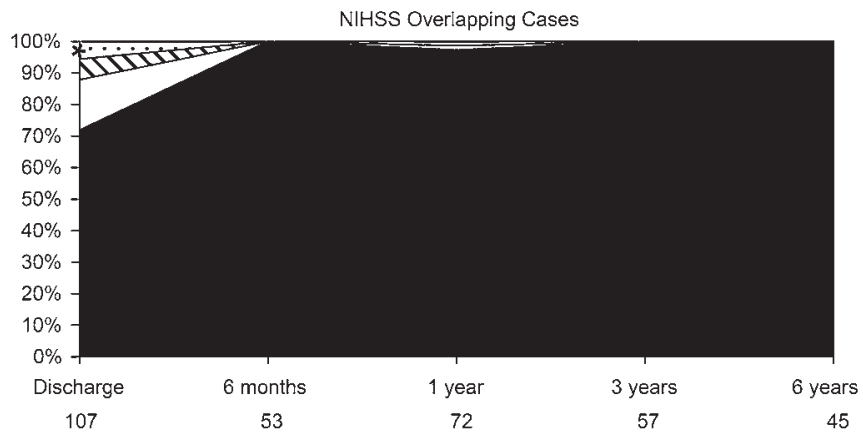

$\mathrm{F}$

FIG. 2. Proportion of patients with defined outcomes at the corresponding follow-up time points for various measures: Barthel Index (BI) scores for nonoverlapping (A) and overlapping (B) cases; MMSE scores for nonoverlapping (C) and overlapping (D) cases; and NIHSS scores for nonoverlapping $(E)$ and overlapping $(F)$ cases. The proportion of patients with NIHSS scores of 21-42 was significantly higher in the nonoverlapping group at discharge $\left({ }^{*} p=0.04\right)$. No significant differences were observed in comparisons of proportions at any of the other collected time points. Numbers under the graphs indicate the number of patients at each time point.

than for the nonoverlapping group. Possible explanations for these findings include benefits of improved operative efficiency with overlapping cases, benefits of resident involvement in overlapping cases with the involvement of the attending physician being focused on the critical portions of the procedure, and unmeasured variations in case complexity. It is important to note that this statistically significant difference was found only at discharge, with rates of obliteration being similar between the groups at the 1-, 3-, and 6-year follow-up. Nonetheless, it is fair to conclude that excellent outcomes of aneurysm obliteration were achieved in overlapping cases.

The second important finding in this study is the lack of significant difference in short-term outcomes, such as length of surgery, LOS, shunt dependence, in-hospital complications, or death. These short-term outcomes are the cornerstone for evaluating the safety of any surgical practice, and the fact that there were no significant differences in operative complications between the 2 groups is a key finding when evaluating the safety of overlapping surgery.

The third important finding is the lack of difference in long-term outcomes on all measured scales up to 6 years postoperatively in these 2 groups, including scores from mRS, GOS, NIHSS, MMSE, and the Barthel Index. One can argue that these prospectively collected measures of 
TABLE 4. Detailed outcome scores at all time points for nonoverlapping versus overlapping cases

\begin{tabular}{|c|c|c|c|c|c|c|}
\hline \multirow[b]{2}{*}{ Variable } & \multicolumn{3}{|c|}{ No Overlap $(n=118)$} & \multicolumn{3}{|c|}{ Overlap $(n=123)$} \\
\hline & No. of Patients & Median Score (range) & Mean \pm SD & No. of Patients & Median Score (range) & Mean \pm SD \\
\hline \multicolumn{7}{|l|}{ Barthel Index } \\
\hline Discharge & 107 & $70(0-100)$ & $57.3 \pm 38.0$ & 111 & $60(0-100)$ & $56.0 \pm 34.7$ \\
\hline $6 \mathrm{mos}$ & 90 & $100(5-100)$ & $93.3 \pm 17.1$ & 85 & $100(0-100)$ & $94.1 \pm 18.7$ \\
\hline $1 \mathrm{yr}$ & 89 & $100(25-100)$ & $95.0 \pm 12.7$ & 93 & $100(5-100)$ & $95.6 \pm 15.3$ \\
\hline 3 yrs & 82 & $100(5-100)$ & $95.1 \pm 14.6$ & 88 & $100(10-100)$ & $96.0 \pm 11.8$ \\
\hline $6 \mathrm{yrs}$ & 78 & $100(0-100)$ & $94.2 \pm 16.4$ & 82 & $100(10-100)$ & $92.2 \pm 16.6$ \\
\hline \multicolumn{7}{|l|}{ GOS } \\
\hline Discharge & 118 & $3(1-5)$ & $3.6 \pm 1.0$ & 121 & $3(1-5)$ & $3.5 \pm 0.9$ \\
\hline $6 \mathrm{mos}$ & 102 & $5(1-5)$ & $4.0 \pm 1.3$ & 96 & $5(1-5)$ & $4.0 \pm 1.3$ \\
\hline $1 \mathrm{yr}$ & 102 & $5(1-5)$ & $4.1 \pm 1.4$ & 107 & $5(1-5)$ & $4.0 \pm 1.4$ \\
\hline 3 yrs & 97 & $5(1-5)$ & $3.9 \pm 1.4$ & 105 & $5(1-5)$ & $4.0 \pm 1.5$ \\
\hline $6 \mathrm{yrs}$ & 94 & $4.5(1-5)$ & $3.8 \pm 1.5$ & 103 & $5(1-5)$ & $3.7 \pm 1.6$ \\
\hline \multicolumn{7}{|l|}{ MMSE } \\
\hline Discharge & 105 & $24(0-30)$ & $18.8 \pm 11.3$ & 109 & $24(0-30)$ & $19.2 \pm 10.6$ \\
\hline $6 \mathrm{mos}$ & 47 & $29(4-30)$ & $27.1 \pm 5.1$ & 53 & $29(15-30)$ & $27.8 \pm 3.3$ \\
\hline $1 \mathrm{yr}$ & 66 & $29(4-30)$ & $27.8 \pm 4.2$ & 72 & $29(13-30)$ & $27.8 \pm 2.9$ \\
\hline $3 \mathrm{yrs}$ & 67 & $29(0-30)$ & $26.9 \pm 5.6$ & 57 & $29(19-30)$ & $28.2 \pm 2.6$ \\
\hline $6 \mathrm{yrs}$ & 50 & $29(13-30)$ & $27.9 \pm 3.4$ & 45 & $29(20-30)$ & $27.7 \pm 2.6$ \\
\hline \multicolumn{7}{|l|}{ NIHSS } \\
\hline Discharge & 103 & $1(0-37)$ & $6.0 \pm 9.5$ & 107 & $1(0-35)$ & $4.7 \pm 7.4$ \\
\hline $6 \mathrm{mos}$ & 48 & $0(0-17)$ & $1.3 \pm 2.8$ & 53 & $0(0-2)$ & $0.6 \pm 0.8$ \\
\hline $1 \mathrm{yr}$ & 66 & $0(0-9)$ & $0.7 \pm 1.6$ & 72 & $0(0-28)$ & $1.1 \pm 3.5$ \\
\hline $3 \mathrm{yrs}$ & 67 & $0(0-20)$ & $0.9 \pm 2.6$ & 57 & $0(0-3)$ & $0.3 \pm 0.8$ \\
\hline $6 \mathrm{yrs}$ & 50 & $0(0-4)$ & $0.5 \pm 0.9$ & 45 & $0(0-3)$ & $0.4 \pm 0.7$ \\
\hline \multicolumn{7}{|l|}{$\mathrm{mRS}$} \\
\hline Discharge & 118 & $3.5(0-6)$ & $3.3 \pm 1.6$ & 121 & $4(0-6)$ & $3.4 \pm 1.4$ \\
\hline $6 \mathrm{mos}$ & 102 & $1(0-6)$ & $2.1 \pm 1.9$ & 96 & $2(0-6)$ & $2.1 \pm 1.8$ \\
\hline $1 \mathrm{yr}$ & 102 & $1(0-6)$ & $2.0 \pm 1.9$ & 107 & $1(0-6)$ & $2.0 \pm 2.0$ \\
\hline $3 \mathrm{yrs}$ & 97 & $1(0-6)$ & $2.1 \pm 2.1$ & 105 & $1(0-6)$ & $2.1 \pm 2.1$ \\
\hline $6 \mathrm{yrs}$ & 94 & $2(0-6)$ & $2.3 \pm 2.1$ & 103 & $2(0-6)$ & $2.4 \pm 2.2$ \\
\hline
\end{tabular}

long-term functional outcomes in our patients represent a rigorous way to evaluate the outcomes of any surgical intervention.

Taken together, these results do not support the claim that the practice of overlapping surgery is unsafe for patients in cases of aneurysmal SAH. In our opinion, the risk of overlapping surgery should be most apparent in a complex procedure like ruptured aneurysm clipping; however, our results demonstrate no significant difference.

This study is not without limitations, including the fact that it is a retrospective analysis of a prospectively collected database. The retrospective design of this study carries all the limitations of a study of this nature. We included a comprehensive list of outcome measures as an attempt to avoid any potential biases. In addition, although patient demographics and clinical characteristics were well matched in this study, differences in aneurysm location did exist, with more posterior circulation aneurysms being present in the overlapping group. This would actually predispose the overlapping group to worse outcomes due to the com- plexity of these aneurysms, which must be considered when interpreting these results. ${ }^{12}$ It is possible that our sample size was too small to detect differences between the groups, predisposing our analysis to a Type II error. Future analyses examining larger case numbers for this population are warranted. Lastly, it is possible that a selection bias was present for surgeons to schedule a case as overlapping, but this is unlikely because all SAH patients were treated as soon as feasible after admission.

\section{Conclusions}

Overlapping surgery, as practiced at our institution for cases included in the BRAT, was not associated with worse outcomes in any of the short- or long-term outcomes for patients who underwent microsurgical clipping of a ruptured aneurysm. These results argue against the claim that the practice of overlapping surgery is unsafe for patients. These findings should be considered during the discussion of future guidelines on overlapping surgery. 


\section{Acknowledgments}

We thank the staff of Neuroscience Publications at Barrow Neurological Institute for assistance with manuscript preparation.

\section{References}

1. Abelson J, Saltzman J, Kowalczyk L, Allen S: Clash in the name of care. Boston Globe. (https://apps.bostonglobe.com/ spotlight/clash-in-the-name-of-care/story) [Accessed on June 23, 2017]

2. American Association of Neurological Surgeons: Position Statement on Intraoperative Responsibility of the Primary Neurosurgeon. (http://www.aans.org/ /link.aspx?_id= 8FA6415D87CE49D49052F0474FD39CFF\&_z=z) [Accessed June 23, 2017]

3. American College of Surgeons: Statement on Principles. (https://www.facs.org/about-acs/statements/stonprin) [Accessed June 23, 2017]

4. Beasley GM, Pappas TN, Kirk AD: Procedure delegation by attending surgeons performing concurrent operations in academic medical centers: balancing safety and efficiency. Ann Surg 261:1044-1045, 2015

5. Bohl MA, Mooney MA, Sheehy JP, Cantwell AM, Chang SW, Chapple KM, et al: Overlapping surgeries are not associated with worse patient outcomes: Retrospective multivariate analysis of 14,872 neurosurgical cases performed at a single institution. Neurosurgery [epub ahead of print], 2017

6. Bonita R, Beaglehole R: Modification of Rankin Scale: Recovery of motor function after stroke. Stroke 19:1497-1500, 1988

7. Fisher CM, Kistler JP, Davis JM: Relation of cerebral vasospasm to subarachnoid hemorrhage visualized by computerized tomographic scanning. Neurosurgery 6:1-9, 1980

8. Folstein M, Folstein SE, McHugh PR: "Mini-Mental State." A practical method for grading the cognitive state of patients for the clinician. J Psychiatr Res 12:189-198, 1975

9. Guan J, Brock AA, Karsy M, Couldwell WT, Schmidt $\mathrm{MH}$, Kestle JR, et al: Managing overlapping surgery: an analysis of 1018 neurosurgical and spine cases. J Neurosurg [epub ahead of print December 2, 2016. DOI: 10.3171/2016.8.JNS161226]

10. Hunt WE, Hess RM: Surgical risk as related to time of intervention in the repair of intracranial aneurysms. J Neurosurg 28:14-20, 1967

11. Hyder JA, Hanson KT, Storlie CB, Glasgow A, Madde NR, Brown MJ, et al: Safety of overlapping surgery at a highvolume referral center. Ann Surg 265:639-644, 2017

12. Jaja BN, Lingsma H, Steyerberg EW, Schweizer TA, Thorpe KE, Macdonald RL: Neuroimaging characteristics of ruptured aneurysm as predictors of outcome after aneurysmal subarachnoid hemorrhage: pooled analyses of the SAHIT cohort. J Neurosurg 124:1703-1711, 2016

13. Jennett B, Bond M: Assessment of outcome after severe brain damage. A practical scale. Lancet 1:480-484, 1975
14. Mahoney FI, Barthel DW: Functional evaluation: the Barthel Index. Maryland State Med J 14:61-65, 1965

15. McDougall CG, Spetzler RF, Zabramski JM, Partovi S, Hills NK, Nakaji P, et al: The Barrow Ruptured Aneurysm Trial. J Neurosurg 116:135-144, 2012

16. Mello MM, Livingston EH: Managing the risks of concurrent surgeries. JAMA 315:1563-1564, 2016

17. Song F, Jerosch-Herold C, Holland R, de Lourdes Drachler M, Mares K, Harvey I: Statistical methods for analysing Barthel scores in trials of poststroke interventions: a review and computer simulations. Clin Rehabil 20:347-356, 2006

18. Spetzler RF, McDougall CG, Albuquerque FC, Zabramski JM, Hills NK, Partovi S, et al: The Barrow Ruptured Aneurysm Trial: 3-year results. J Neurosurg 119:146-157, 2013

19. Spetzler RF, McDougall CG, Zabramski JM, Albuquerque FC, Hills NK, Russin JJ, et al: The Barrow Ruptured Aneurysm Trial: 6-year results. J Neurosurg 123:609-617, 2015

20. Teasdale G, Jennett B: Assessment of coma and impaired consciousness: a practical scale. Lancet 2:81-84, 1974

21. United States Senate Finance Committee: Concurrent and Overlapping Surgeries: Additional Measures Warranted. (https://www.finance.senate.gov/imo/media/doc/ Concurrent $\% 20$ Surgeries\%20Report $\% 20$ Final.pdf) [Accessed June 23, 2017]

22. Uyttenboogaart M, Stewart RE, Vroomen PC, De Keyser J, Luijckx GJ: Optimizing cutoff scores for the Barthel index and the modified Rankin scale for defining outcome in acute stroke trials. Stroke 36: 1984-1987, 2005

23. Zygourakis CC, Lee J, Barba J, Lobo E, Lawton MT: Performing concurrent operations in academic vascular neurosurgery does not affect patient outcomes. J Neurosurg [epub ahead of print January 20, 2017. DOI: 10.3171/2016.6.JNS16822]

\section{Disclosures}

The authors report no conflict of interest concerning the materials or methods used in this study or the findings specified in this paper.

\section{Author Contributions}

Conception and design: Spetzler, Mooney, Bohl, Sheehy. Acquisition of data: Mooney, Brigeman, Sheehy. Analysis and interpretation of data: Spetzler, Mooney, Brigeman, Simon. Drafting the article: Mooney, Brigeman, Simon. Critically revising the article: Spetzler, Bohl, Chang. Reviewed submitted version of manuscript: Spetzler. Statistical analysis: Mooney, Brigeman. Study supervision: Spetzler.

\section{Correspondence}

Robert F. Spetzler, c/o Neuroscience Publications, Barrow Neurological Institute, St. Joseph's Hospital and Medical Center, 350 W Thomas Rd., Phoenix, AZ 85013. email: neuropub@ dignityhealth.org. 